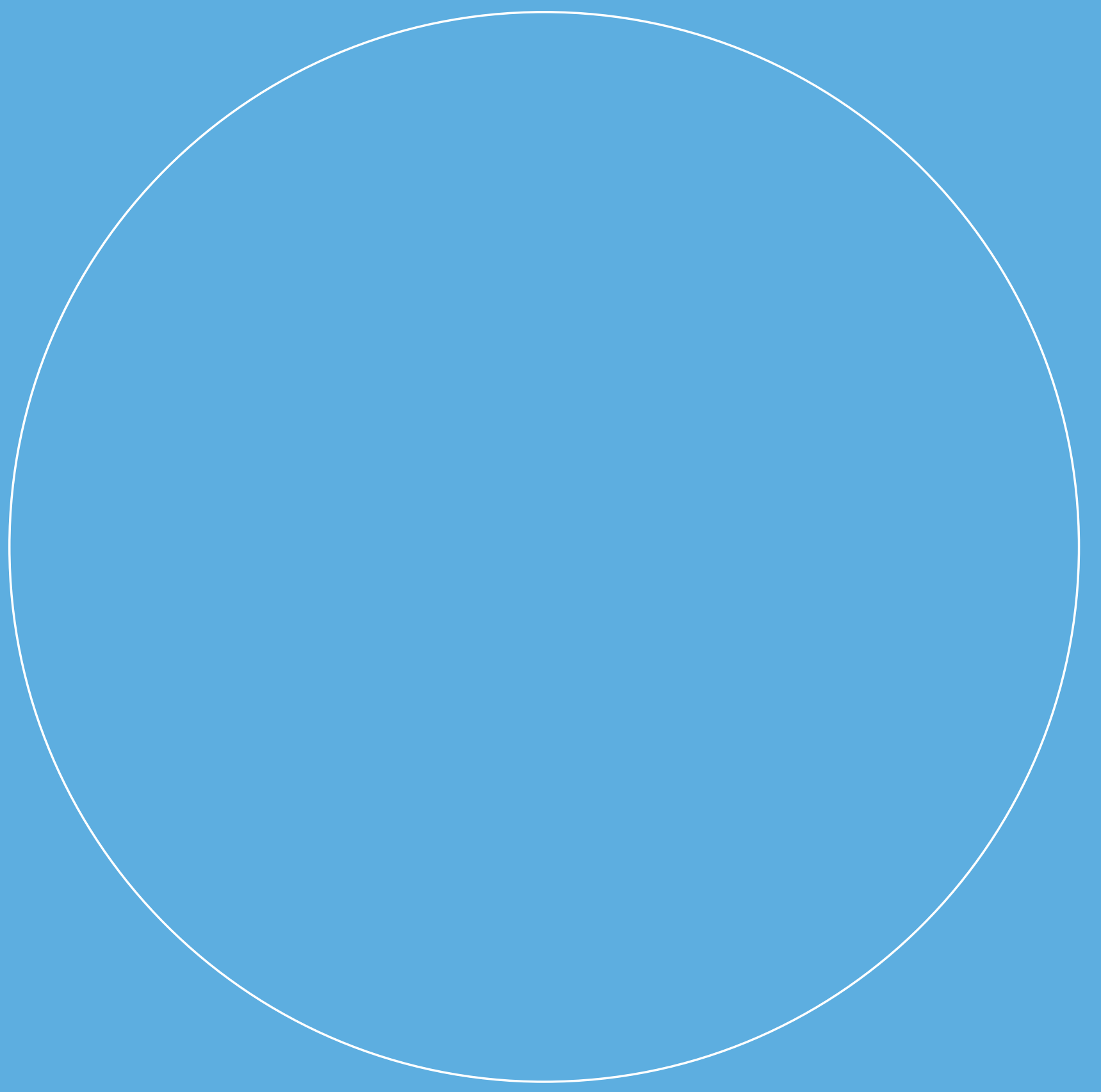

\title{
Effects of Starchy edible coating on shelf life of apples
}

Fátima Pereira da Silva, Maxence Paillart 


\section{Effects of Starchy edible coating on shelf life of apples}

Authors: Fátima Pereira da Silva, Maxence Paillart

This research project has been carried out by Wageningen Food \& Biobased Research commissioned by Starchy and funded by Berytech, in the context of Statup hub (project number 6239155300). 
Version: final

Confidential until: July 2021

Reviewer: Jan Verschoor

Approved by: Nicole Koenderink

Client: Starchy

Sponsor: Berytech

(c) 2018 Wageningen Food \& Biobased Research, institute within the legal entity Stichting Wageningen Research.

Nothing from this publication may be reproduced and/or made public without prior written permission by the director of Wageningen Food \& Biobased Research.

This report can be downloaded for free from January 2024 at https://doi.org/10.18174/563053/ or at www.wur.nl/wfbr (under publications).

PO box 17, 6700 AA Wageningen, The Netherlands, $T+31$ (0)317 480084 , E info.wfbr@wur.nl, www.wur.eu/wfbr. Wageningen Food \& Biobased Research is part of Wageningen University \& Research.

All rights reserved. No part of this publication may be reproduced, stored in a retrieval system of any nature, or transmitted, in any form or by any means, electronic, mechanical, photocopying, recording or otherwise, without the prior permission of the publisher. The publisher does not accept any liability for inaccuracies in this report. 


\section{Contents}

$\begin{array}{ll}\text { Summary } & 4\end{array}$

$1 \quad$ Introduction $\quad 5$

2 Experimental set and methods $\quad 6$

2.1 Test variables $\quad 6$

$\begin{array}{lll}2.2 & \text { Test description } & 6\end{array}$

$\begin{array}{ll}2.3 \text { Measurements } & 7\end{array}$

2.3.1 Weight loss: $\quad 7$

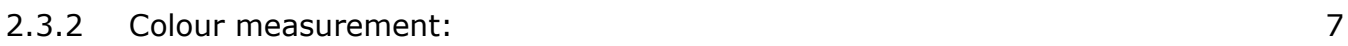

2.3.3 Firmness measurement: $\quad 8$

2.3.4 External/internal defects assessment: $\quad 8$

2.3.5 Sensorial evaluation: $\quad 8$

$3 \quad$ Results and discussion $\quad 10$

$\begin{array}{lll}3.1 & \text { Drying and storage conditions } & 10\end{array}$

3.2 Initial quality 11

3.3 Weight losses $\quad 12$

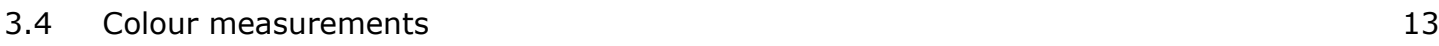

$\begin{array}{llr}3.5 & \text { Firmness } & 15\end{array}$

$\begin{array}{ll}3.6 & \text { Quality defects } \\ 3.7 & 15\end{array}$

$\begin{array}{llr}3.7 & \text { Sensorial analysis } & 18\end{array}$

4 Conclusions $r \begin{aligned} & 19\end{aligned}$

$5 \quad$ Recommendation $r$

$\begin{array}{ll}\text { Annex 1: Questionnaire sensorial evaluation } & 21\end{array}$ 


\section{Summary}

Starchy, a Lebanese start up, has elaborated a starch-based coating to preserve and extend the quality of fresh fruit such as apples or pears. In order to get insight in the performance of the coating the company has been interested in testing its coating on an European apple variety. Subsequently Starchy has received financial support of Agrytech to set up a project with Wageningen Food \& Biobased Research (WFBR). The goal of the project was to study the effects of the Starchy edible coating on shelf life of apples (Elstar). The research was conducted independently.

Wageningen Food \& Biobased Research (WFBR) has drawn an experiment set-up in order to test on a scientific basis the effect of such a new coating on apple quality. The starch-based coating was tested at two dilutions on four batches of apples and under two shelf life conditions to simulate a normal and a more challenging chain with more risk of dehydration. The present document reports the set-up and results observed on the coated and uncoated apples, as well as the main conclusions.

Although the test was designed to find effects of the coating on fruit quality by for instance reducing humidity during shelf life (to be able to show protective effects on water loss) and using stored mature fruits (more sensitive to develop quality issues in the subsequent chain) the differences between the coated and uncoated apples are very limited or not present al all:

- Apples coated with the thicker coating receipt remained statistically firmer than the apples coated with the most fluid coating or uncoated, but this effect was very limited $(<0.2 \mathrm{~kg}$ ). There was no difference between the more fluid coating and the uncoated apples.

- $\quad$ No significant effect on the outside and inside quality attributes and defects were observed when applying a starch-based coating on the apples.

- No significant effect of the coating on the yellowing of the apples was found (yellowing is a relevant quality indicator; the more yellow the riper the apple). A significant effect of the coating on the other colour parameters was observed during the shelf life period: coated apples were slightly darker and more red after one week of storage compared to the uncoated apple. These colour parameters are however not directly linked to the physiological shelf life of the apples.

- The sensorial analysis did not show any significant effects of the starch-based coating on the quality perception of the fresh-cut apples.

- Concerning the effect on the water loss, no definitive conclusion can be drawn as it could be that the coated apples were not fully dried out at the time of the first weighing measurement. This may have influenced the weight loss calculation and led to incorrect conclusions about the effect of the starch based coating on the weight loss rate.

- $\quad$ On the day after the coating application, the coated apples seemed to have higher gloss than uncoated apples (This is a general observation; the level of glossiness was not scored).

These conclusions apply for the scope of this test (cultivar, maturity level, storage conditions, etc). Other cultivars or longer storage periods may lead to different conclusions. However no extrapolations can be done for other situations based on the current research. In retrospect, factors such as cultivar, the use of more mature fruits (the used cultivar Elstar had been stored for 8-9 months under CA conditions in a commercial CA store, which means the fruits had limited storability left) might however also have limited the observed effects of the coatings. Moreover a simulation of the industrial coating application has been used in this research. Under optimised industrial conditions (for instance other drying process) the performance of the coating might be different.

It is recommended to improve the coating formulation in order to enhance the small effect found on firmness and to prevent the coating from being unpleasantly sticky as observed in part of the coated fruits in this test. 


\section{Introduction}

Starchy is a start-up from Lebanon and has received the support of Agrytech (the Agrytech Program supports top innovative start-ups by providing them with the adequate technical and business resources). The innovation development of Starchy is an edible coating to be applied on fresh produce. Currently tests are running in Lebanon in collaboration with the Industrial Research Institute (IRI) to get certifications of the product claims. In order to have a more solid fundament for commercial implementation, validation tests of the application as well as the scaling of the production process and shelf life of the coating itself are needed. In the light of this the Postharvest Technology group of Wageningen Food \& Biobased Research (WFBR) was contacted to set up a project.

The goal of the project was to study the effects of the Starchy edible coating on shelf life of apples. It was expected that the application of the coating layer will decrease moisture losses and reduce gas exchange between the fruit and the surrounding air. Both these aspects can affect the shelf life of apples. The focus of this project was to test if the application of the coating can result in a significant increase in the shelf life.

The research was conducted independently and the results are documented in this report. The next chapter describes the experimental test set-up and methodology used. Afterwards the results are presented and discussed. The report is finished with the most important conclusions and recommendations of this study. The report is intended for Starchy. 


\section{Experimental set and methods}

\section{$2.1 \quad$ Test variables}

To test the effect of the coating on the shelf life, four apple batches were coated and not coated and stored under two shelf life conditions. After storage the quality was assessed.

\section{Apples}

Table 1 shows the details of the four apple batches cv. Elstar used in this research, combining different orchards/origins and harvesting moments. The apples were stored under DCA (=Dynamic Control Atmosphere) conditions: $0.5 \%-0.8 \% \mathrm{O}_{2}$ and $2 \% \mathrm{CO}_{2}$. The fruitswere removed from storage on the $21^{\text {st }}$ of May 2018 and kept at around $10^{\circ} \mathrm{C}$ until Monday the $28^{\text {th }}$ of May when the apples were transported to Wageningen. Experimental unit size consisted of 18 apples in duplicate. This means that for all variables (orchards/harvests, coating, shelf life conditions, moment of quality evaluation in the chain) $2 \times 18$ fruits were used.

\section{Table 1: Details of the four apple batches used in the test.}

\begin{tabular}{|l|l|l|l|l|}
\hline Batch & Cultivar & Orchard/origin & Harvest & Batch code \\
\hline 1 & Elstar Excellent & Orchard A & Early $\left(11^{\text {th }}\right.$ September 2017$)$ & A_E \\
\hline 2 & Elstar Excellent & Orchard A & Late $\left(17^{\text {th }}\right.$ September 2017$)$ & A_L \\
\hline 3 & Elstar Excellent & Orchard B & Late $\left(18^{\text {th }}\right.$ September 201 & B \\
\hline 4 & Elstar Elrosa & Orchard C & Early $\left(13^{\text {th }}\right.$ September 2017$)$ & C \\
\hline
\end{tabular}

\section{Coatings}

Two type of coatings (different concentrations) were tested: coating 1 and coating 2 . The reference batch was not coated.

Chain conditioning

Each of these test variables were stored at 2 different shelf life conditions. This gives 6 test variables. Both the reference apples and each coating type/concentration in combination with the 2 shelf life conditions were applied in duplicate. In total 12 test applications. Each apple batch was assessed for these 12 test applications.

Shelf life conditions

The two shelf life variables were:

Shelf life $1: 20^{\circ} \mathrm{C}$ and $35 \% \mathrm{RH}$ (shelf life conditions middle east)

Shelf life $2: 20^{\circ} \mathrm{C}$ and $60 \% \mathrm{RH}$ (shelf life conditions retail and consumer in North Europe)

In both cases the shelf life duration is 8 days.

\subsection{Test description}

Upon arrival de apples were stored at $1^{\circ} \mathrm{C} 90 \% \mathrm{RH}$ until processing (2 days). In the night before starting the test the temperature of the storage cell was increased to $5^{\circ} \mathrm{C}$ to ensure that all apples were at $5^{\circ} \mathrm{C}$ for the application of the coating.

The coating was prepared by the personnel of Starchy. Coating 1 was prepared and applied in the morning. Afterwards the reference apples were prepared and finally coating 2 was prepared and applied in the afternoon. The air temperature during the preparation of the samples was kept at $20^{\circ} \mathrm{C}$. According to the information given by Starchy, both coatings were made of the same components, only the fluidity (density) between the two coatings differed: coating 1 was thicker than the coating 2 . 
The apples of each batch were randomly distributed into the 3 treatments (reference, coating 1, coating 2) and a number of apples for the assessment of the batch initial quality. The apples were washed for 1 minute in a large basin with tap water at $15^{\circ} \mathrm{C}(180 \mathrm{~L})$. The apples of each treatment (initial quality, coating 1, coating 2 and reference) were washed together. Between these "sub-batches" the water was not refreshed. However between the four apple batches ( A-early, A- Late, B and C) the water was completely refreshed. After washing, the apples were kept at $5-6^{\circ} \mathrm{C}$ until the start of the treatment.

For each test variable and duplicate treatments, a sample of 18 apples was prepared as follows:

- Before the application of the coating, the washed apples were dried with tissue paper, making sure that no water stays at the peduncle.

- $\quad$ The coating was applied manually with a soft brush evenly on the entire fruit. The temperature of the coating was at $40-45^{\circ} \mathrm{C}$. The coated apples were placed on aluminium foil till drying.

- Apples were dried with warm air (approx. $35^{\circ} \mathrm{C}$ ) using a shrink-wrap machine. The machine was run 8 times (12 seconds per run) until the coating was completely dry time (visual check). The internal and external temperature of apple achieved during the drying process is presented in the results.

- The 18 apples of each sample object were placed in a plastic crate, crates were divided over the two shelf life rooms.

- The reference apples were handled the same way, except for the application of the coating and the time of warm air drying. The visual dryness was achieve in 5 runs instead of 8 because the coated fruits took longer to dry. The apples for the initial quality assessment were put in crates and kept at $20^{\circ} \mathrm{C}$ and $60 \%$ Relative Humidity $(\mathrm{RH})$ till the next day in the morning when the assessment of the initial quality was started.

\subsection{Measurements}

The quality assessment was performed before applying the coating (initial quality assessment) and after one week shelf life storage treatment. The initial quality assessment consists of measuring the colour, the firmness and determine any external/internal defects. For the shelf life after 8 days, the weight loss, the colour, the firmness, the external/internal defects assessment and a sensorial evaluation were measured.

\subsubsection{Weight loss:}

The weight loss was measured by weighing the samples (and the empty crate) before and after shelf life. The weight loss is expressed in percentage of weight loss between the end and the beginning of the storage period. The initial weight was measured within 2-3 hours after applying the coating treatment.

\subsubsection{Colour measurement:}

After drying the apples, 18 apples were carefully placed on the pre-formed apple sheet in the blue tray. Each apple was placed with its yellow side on top.

The colour was measured with a RGB camera under fixed lighting conditions in a cabinet designed to take calibrated colour pictures.. The images were processed with specific software to calculate a number of colour parameters. Colour of the apples were analysed prior and after the storage weeks. Pictures of the apple trays were taken under the same present conditions. The colour change over one week of storage was analysed on the green/yellow part of the apples. The analysis software selected first the apple area presenting the most yellow colour. The $L, a$ and $b$ values of each pixel included in this area was calculated on basis of the RGG values. The average $L$, $a$ and $b$ values per apple was then reported and the delta values ( 1 week storage - initial) was used for the statistical analysis (General analyse of the variance (ANOVA), Genstat 19.1e edition, VSN International Ltd.). The lightness value, $L$, represents the darkest black at $L=0$, and the brightest white at $L=100$. The a axis represents the green-red component, with green in the negative direction and red in the positive direction. The $b$ axis represents the blue-yellow component, with blue in the negative direction and yellow in the positive direction. 


\subsubsection{Firmness measurement:}

The firmness was measured with a FTA penetrometer (Güss, Strand, South Africa). The apples were perforated in the equatorial region in between the sunny and shaded side of the fruits (halfway the most green and most red side) with an apple probe $(11 \mathrm{~mm}$ diameter). Before the firmness measurement the apple skin was partially removed (only on the small surface where the probe penetrates the apple) and positioned on a tripod holder to avoid any movements during the measurement. The instrument settings are presented in Figure 1.

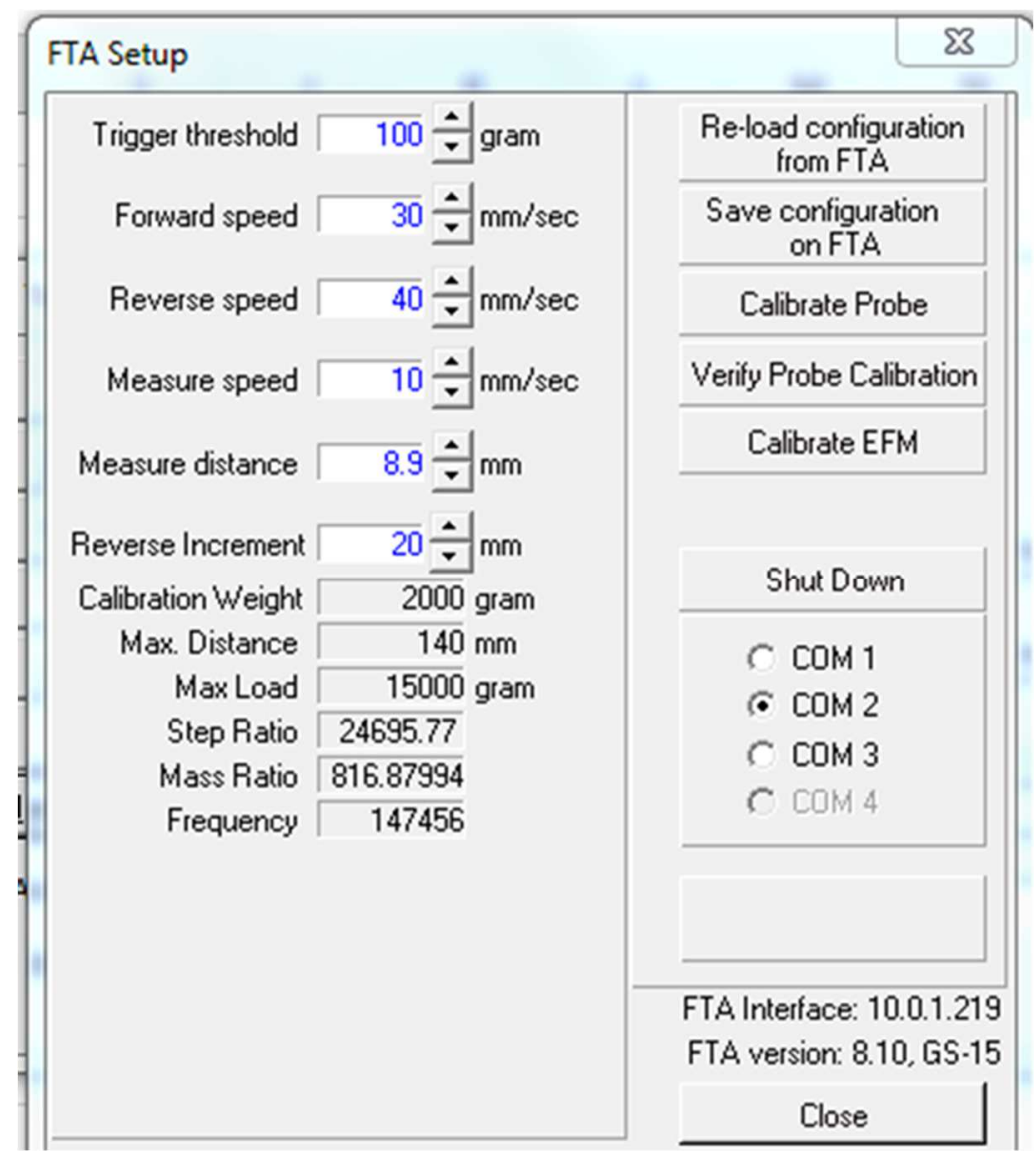

Figure 1: Penetrometer settings.

\subsubsection{External/internal defects assessment:}

The external/internal defects assessment was carried out visually. The following external defects were scored: skin spot-index (0-100\%) and lenticel spot (present or not present). The following internal defects were also scored after cutting the apple in the cross-section:

- Senescence breakdown (present or not present);

- ULO browning (internal browning with cavity formation, related to sensitivity for low $\mathrm{O}_{2} / \mathrm{high}$ $\mathrm{CO}_{2}$ )(present or not present);

- Core infection (present or not present);

- Other defects.

\subsubsection{Sensorial evaluation:}

The sensorial evaluation was done with 5 persons, 3 males and 2 females. Due to the large number of samples, it was not feasible to evaluate all the 4 batches (Orchards and harvest dates). Therefore the sensorial evaluation was carried out with the batch: orchard A; Early harvest (A_E). A large slice of the equatorial region of the fruit with peel was cut in 4 pieces. Only acceptable fruits without rot or senescence breakdown were used for the sensorial evaluation. The panellists were asked to assess at least two pieces of apple per sample and give a score to the taste and odour of the apple sample (see Figure 2). The score scale is from 1 to 10 where $1=$ Very bad, $5=$ Acceptable and $10=$ Excellent. The questionnaire is shown in appendix 1. 


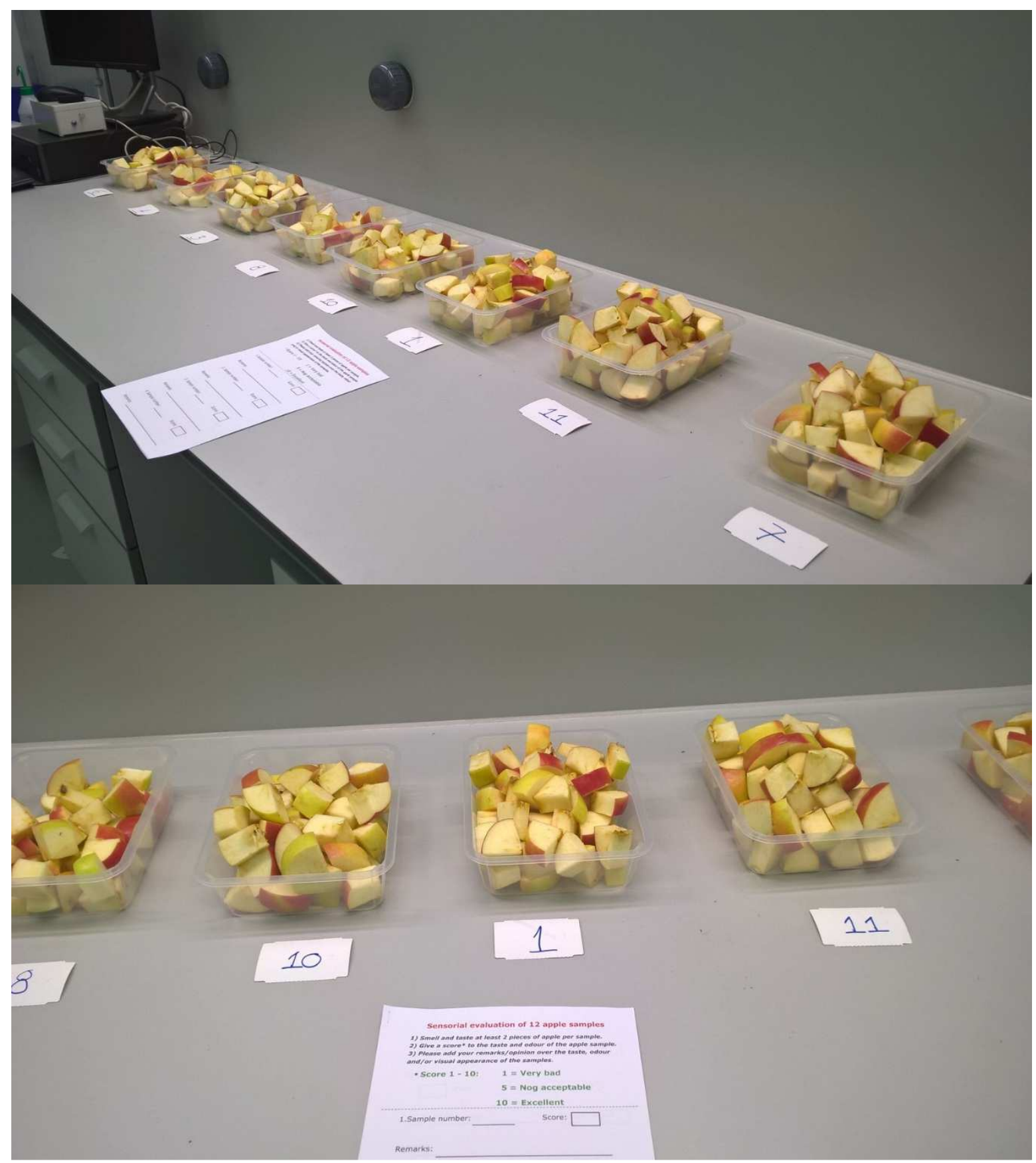

Figure 2: Samples ready for the sensorial evaluation. 


\section{Results and discussion}

\subsection{Drying and storage conditions}

Figure 3 shows the temperature and relative humidity measured in the direct surrounding of the treated apples during the complete duration of the shelf life treatment. The measured Relative Humidity is above the set point (due to moisture loss of the product and lower air circulation close to the crates, the $\mathrm{RH}$ measured closed to the product is slightly higher). The sensor was standing close to the crates/product.

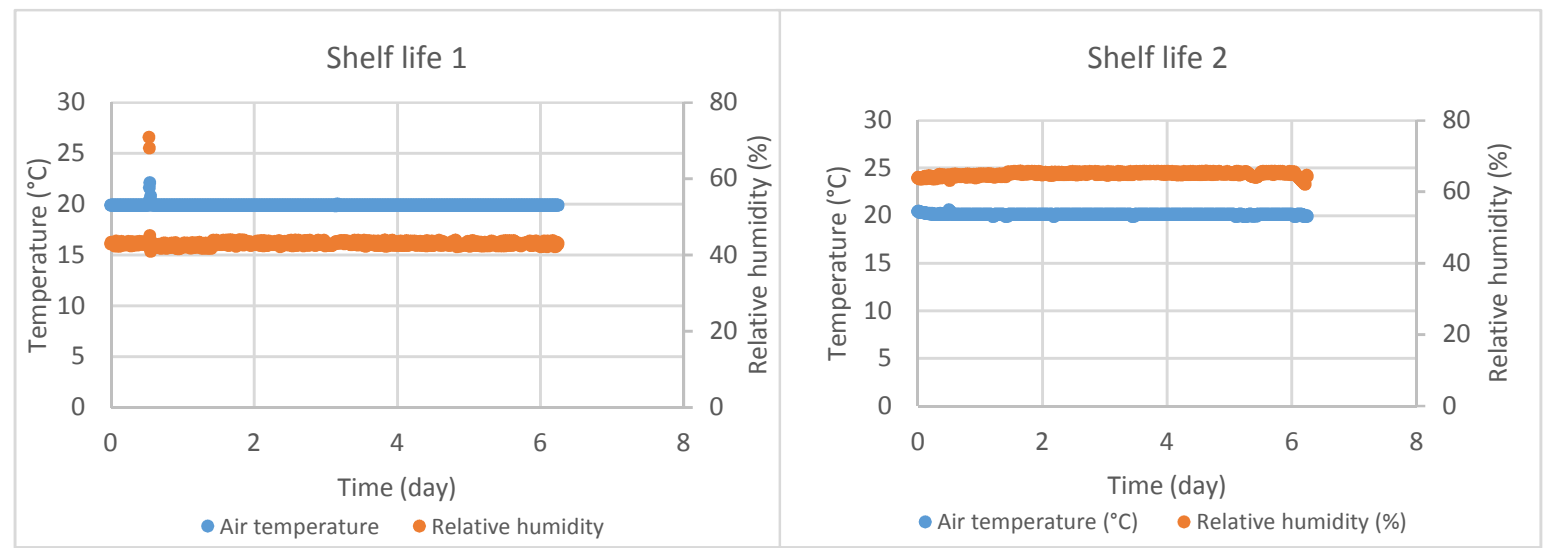

Figure 3: Temperature and relative humidity measured in the direct surrounding of apples during shelf life 1 (simulation shelf life conditions middle east) and shelf life 2 (shelf life conditions retail and consumer in North Europe) storage treatments.

The apples were dried using warm air of approx. $35^{\circ} \mathrm{C}$. using a shrink-wrap machine. The machine was run 8 times (12 seconds per run) until the coating was completely dry time (visual check). Figure 3 shows the internal and external temperature of apple during the drying process.

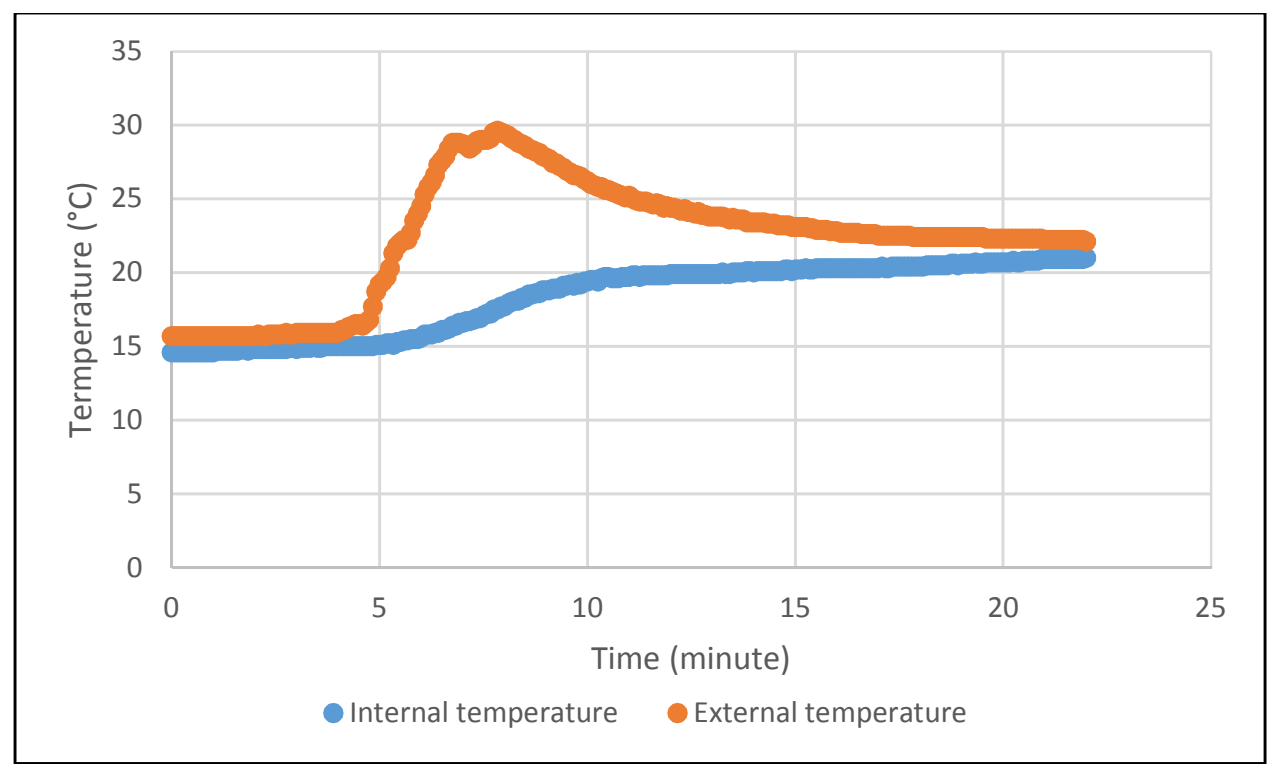

Figure 4: Internal and external temperatures of coated apple during drying process. 


\subsection{Initial quality}

The intrinsic quality of the four research batches was established by measuring the firmness and the amount of internal/external defects. Figure 4 shows the average firmness. Batch A both early and late harvest are statistically significantly more firm than batch B and C.

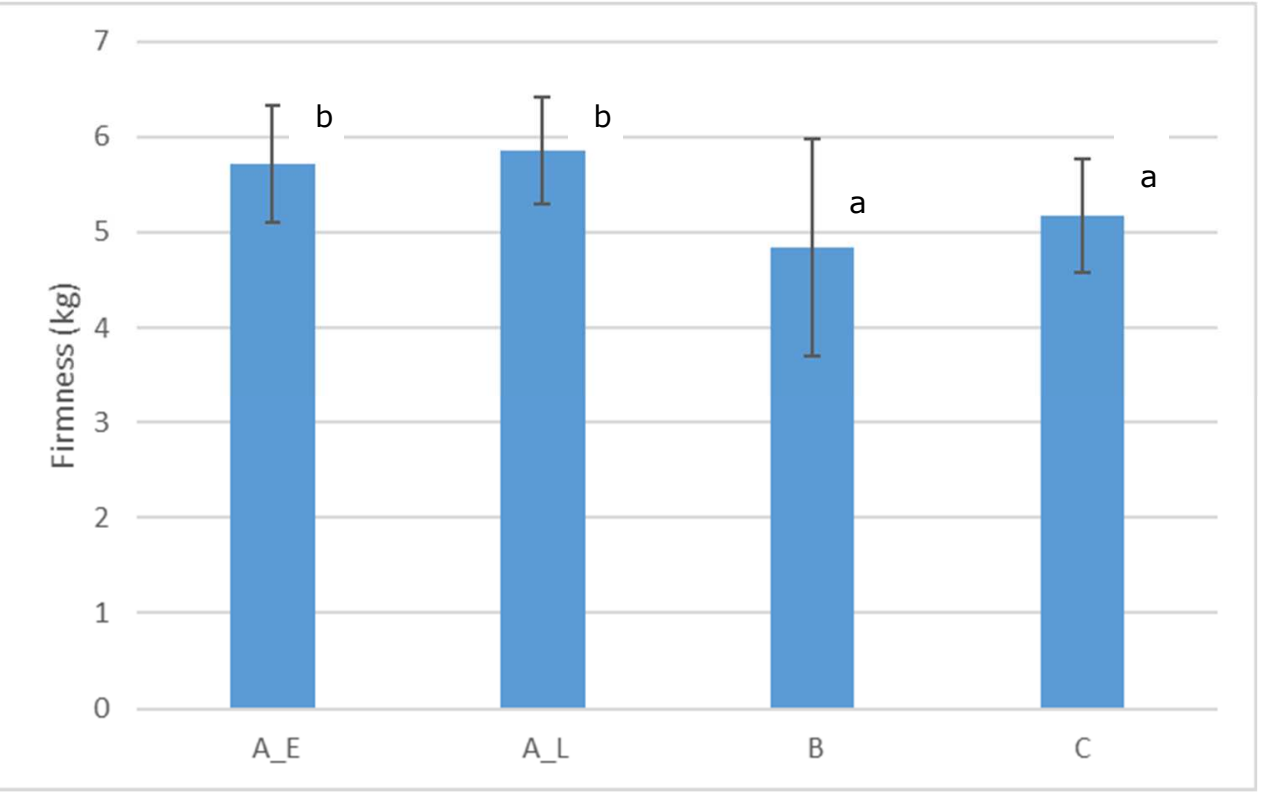

Figure 5: Average firmness and standard deviation (Kg) of the four tested apple batches $(\mathrm{N}=36)$; Significant difference per batch are indicated by the letters (Turkey test, $P<0.05$ ). Batch $A \_E, A \_L$ and $B$ are the same mutant (Excellent) with respectively early, late and late harvest; batch $C$ is the mutant Elrosa from early harvest.

Concerning the assessment of internal and external defects, senescence breakdown was scored as present $(=1)$ and not present $(=0)$ for each apple. The percentage of senescence breakdown was calculated by dividing the number of apples showing senescence breakdown by the total number of apples. The results are presented in Figure 5 . The statistical analysis showed that the percentage senescence breakdown in batch $B$ is significant higher than in batch A_E and $A \_L$. Batch $C$ is not significant different from batch $B$ neither from batch $A$, both early and late harvest. These results are in agreement with the firmness data and indicate the different physiological stages of the four batches.

Next to senescence breakdown, the quality aspects core infection, skin spot, rot and eventual other defects were also assessed. There was no core infection or skin spot observed. There were a few rot apples observed: 2 for batch $B$ and 1 for batch $C$ and none for batch A_E and A_L (out of 36 apples per batch). Also these values are in accordance with the firmness and \% senescence breakdown results discussed here above.

On the day after the coating application, it seemed that the coated apples had higher gloss than the uncoated apples (level of glossiness was not scored; hence this is a general observation). 


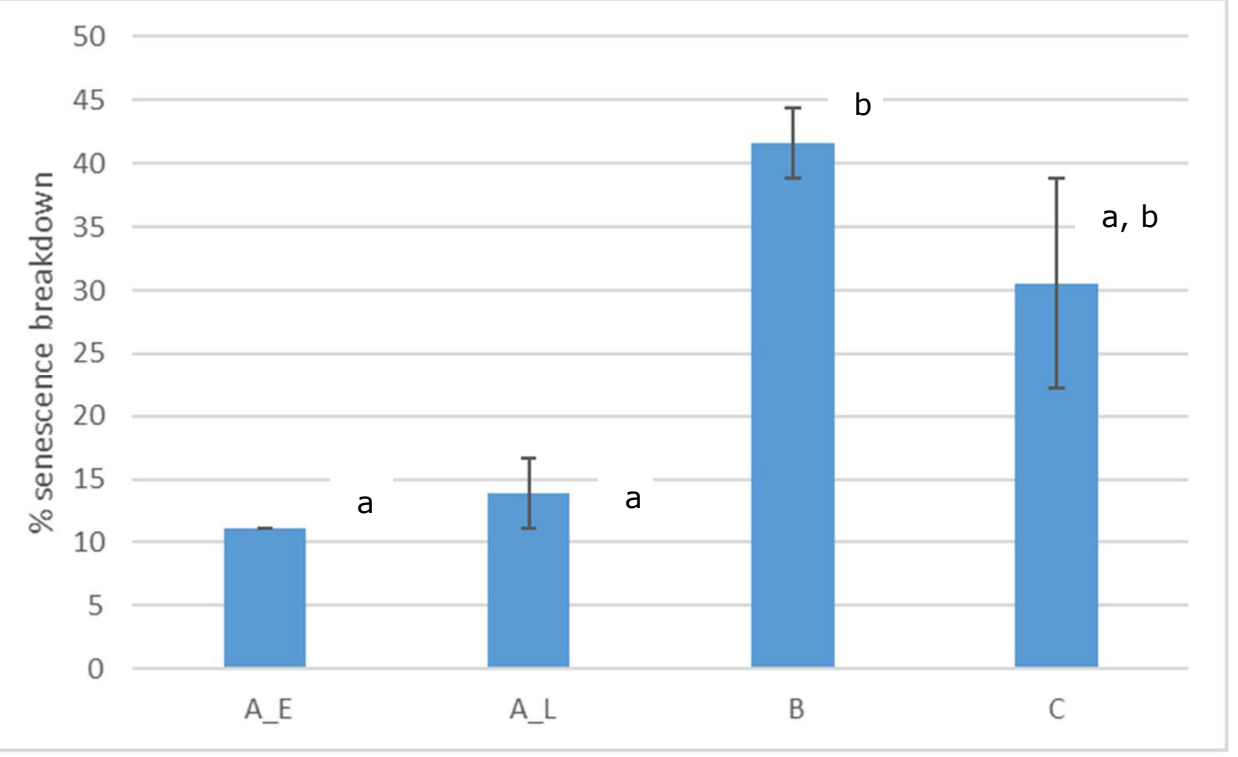

Figure 6: Average senescence breakdown and standard deviation (\%) of the four tested apple batches ( $N=36)$; Significant difference per batch are indicated by the letters (Turkey test, $P<0.05)$. Standard error. Batch $A \_E, A \_L$ and $B$ are the same mutant (Excellent) with respectively early, late and late harvest; batch $C$ is the mutant Elrosa from early harvest.

\subsection{Weight losses}

The graphs in Figure 6 show the weight loss after 8 days at $20^{\circ} \mathrm{C}$ and approximately $42 \%$ or $65 \% \mathrm{RH}$ for the 3 treatments and for the 2 shelf life conditions.

Despite expectations of the coatings reducing water loss, no reduced water loss was observed when comparing coated apples with uncoated Figure 6A).Coating treatment 1 led to more weight loss than coating treatment 2 and the uncoated apples (Figure 6A). These results are not in agreement with what should be expected: coated apples were expected to have less weight loss. In addition coating 1 is thicker and should offer more resistance to moisture loss. Most probably the coating was not fully dried when the crates were weighed at the start of the storage period. Therefore the moisture loss measured includes also the water loss from the coating itself. This also explains the extra moisture loss by the thicker coating (the thicker coating contains in total volume also more water).

According to the statistical analysis, higher weight loss under the shelf life conditions 1 (lower RH) than under shelf life conditions 2 (higher $\mathrm{RH}$ ) was observed, whatever the coating treatment applied Figure $6 \mathrm{~B})$. A lower RH may dry out the apples so more weight loss under these conditions can be expected. Finally, the four apple batches also showed different weight loss levels as presented in Table 2.

From the physiological point of view, batch B shows the most senescence (softer batch and higher senescence breakdown). This batch has also the highest weight loss whereas the batch A_E (less senescence) has the least weight loss. Batch $C$ was also Elstar but another mutant (Elrosa) therefore it is not possible to compare its maturity stage with the other three batches.

Table 2: Average weight loss of the 4 apple batches $(N=36)$; Significant difference per batch are indicated by the letters (Turkey test, $P<0.05$ ).

\begin{tabular}{|l|l|}
\hline Batch & Weight loss (\%) \\
\hline A_E & $2.48 \% ;$ a \\
\hline C & $3.12 \% ; b$ \\
\hline A_L & $3.33 \% ; b$ \\
\hline B & $3.59 \% ; \mathrm{c}$ \\
\hline
\end{tabular}




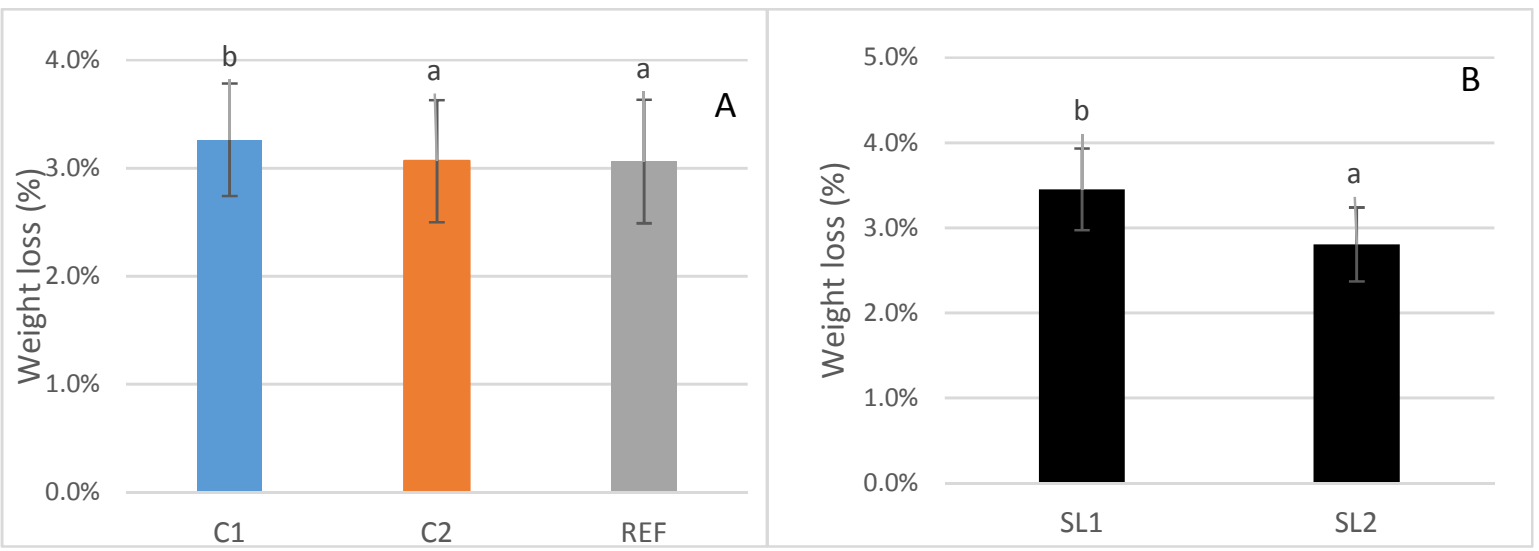

Figure 7: A: Average weight loss and standard deviation (\%) of the three treatments: untreated (ref), treated with coating 1 or 2. $(N=16)$; Significant difference per batch are indicated by the letters (Turkey test, $P<0.05$ ). B: Average weight loss and standard deviation (\%) of the two tested shelf life: $20^{\circ} \mathrm{C}$ and higher relative humidity (SL1) or $20^{\circ} \mathrm{C}$ and lower relative humidity (SL2). ( $N=24)$; Significant difference per batch are indicated by the letters (Turkey test, $P<0.05)$.

\subsection{Colour measurements}

The colour development over one week storage at $18^{\circ} \mathrm{C}$ under high and low relative humidity can be monitored by the delta $L, a$ and $b$ values. The delta values were calculated by subtracting per apple its $L$, $a$ or $b$ value after one week storage by its initial $L$, $a$ or $b$ values.

Figure 7 shows the delta $L$ value of the green/yellow part of the apples. The apples whatever the cultivar, the coating treatment and/or the storage treatment are getting less light over the time. No significant difference were observed when comparing the interaction between the treatments. However regarding the effect between the coating treatments, significant difference between the coatings and the reference was observed (Table 3); Appels coated with coating 1 were getting darker (negative delta value) than the non-coated one.

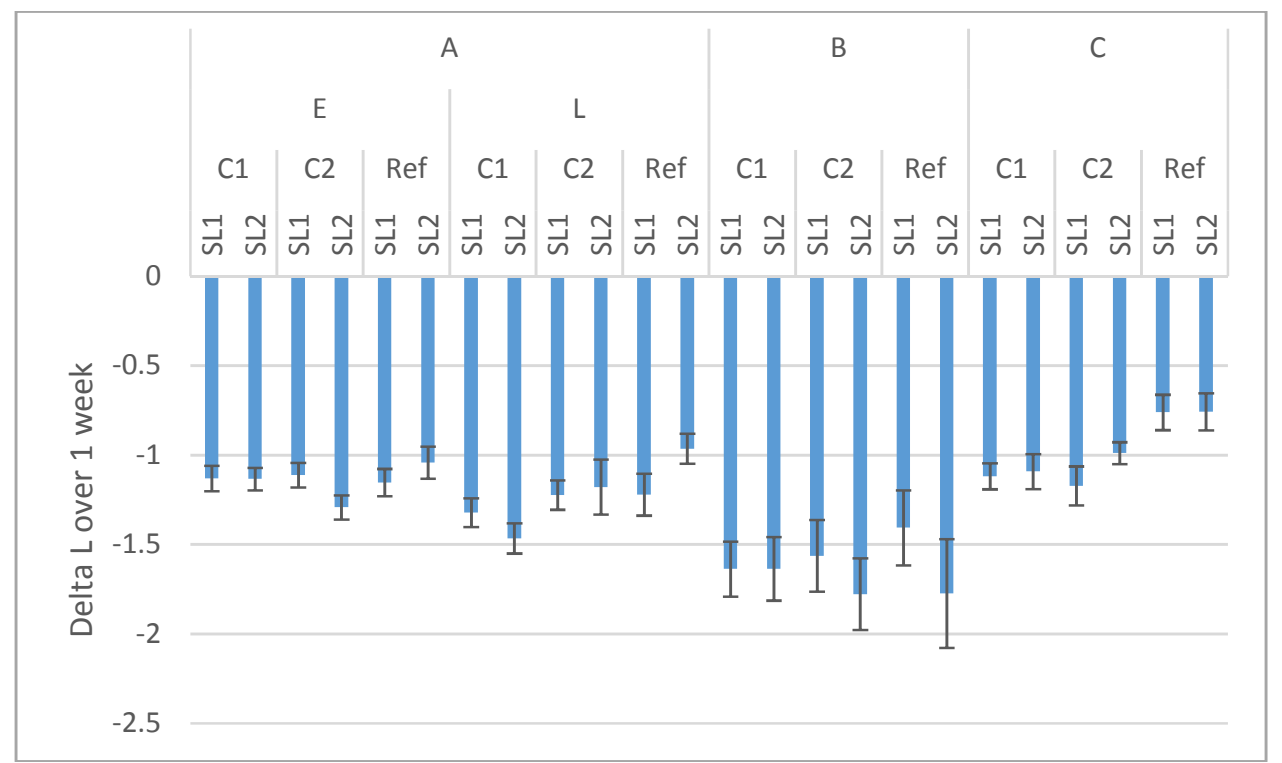

Figure 8: Average Delta L of the yellow part of apples. Apples were untreated (ref), treated with coating 1 or 2 prior storage and stored at $20^{\circ} \mathrm{C}$ and higher relative humidyt (SL1) or $20^{\circ} \mathrm{C}$ and lower relative humidity (SL2). $(\mathrm{N}=36)$ Standard error. 
Table 3: Average delta $L$, a and b per coating treatment. $N=270$. Significant difference per column are indicated by the letters (Turkey test, $P<0.05$ )

\begin{tabular}{|l|l|l|l|l|l|}
\hline & Delta L & & Delta a & & Delta b \\
\hline C1 & -1.321 & a & 1.035 & a & 0.211 \\
\hline C2 & -1.294 & ab & 1.097 & a & 0.303 \\
\hline Ref & -1.143 & b & 1.526 & b & 0.349 \\
\hline
\end{tabular}

Concerning the results delta $a$, an interaction between the coatings, the shelf life and the cultivars treatments was observed (Figure 8): significant difference is represented by the error bars. Although there were statistical difference, no clear patterns can be identified: it seems that cultivar effect was so important that the coating did not react similarly between the cultivars. When regarding only the effect of coatings (Table 3), clear effect of the coating treatment on the delta a values were observed, meaning that the coated apples were getting more red during the storage than the uncoated apples.

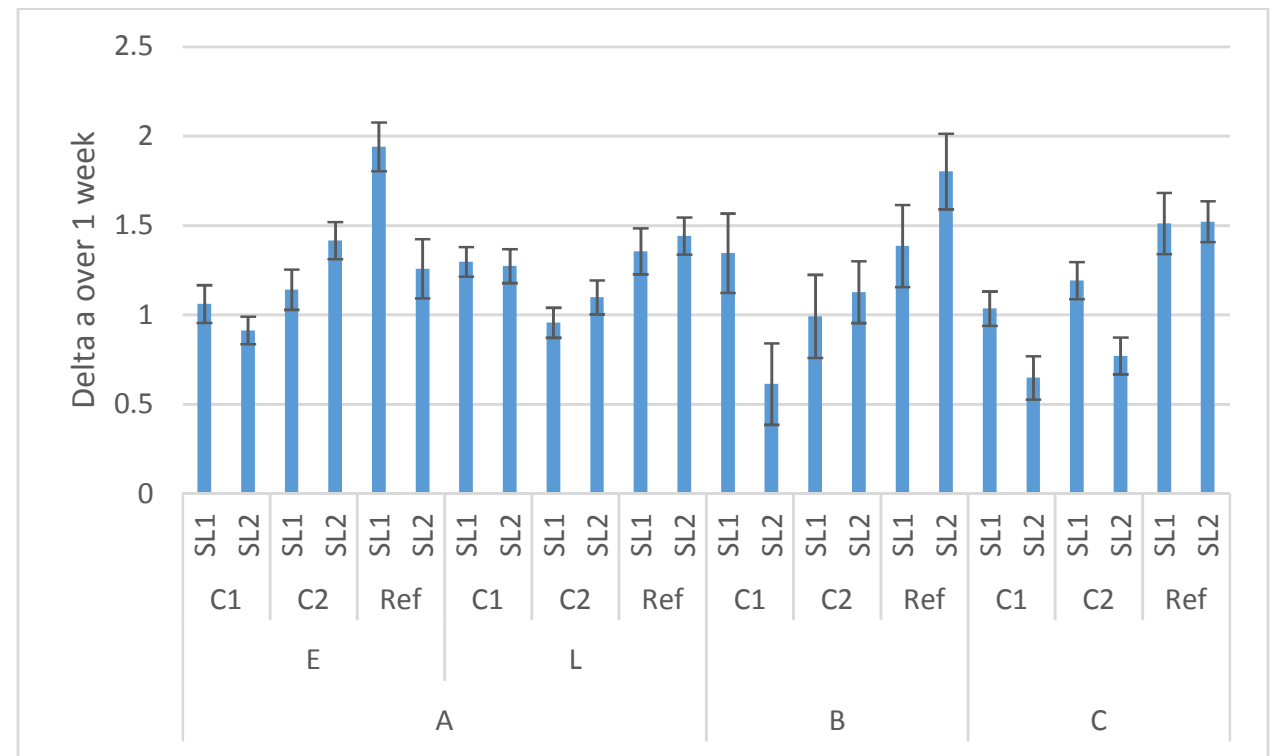

Figure 9: Delta a values of the yellow part of apples. Apples were untreated (ref), treated with coating 1 or 2 prior storage and stored at $20^{\circ} \mathrm{C}$ and $60 \%$ relative humidyt (SL1) or $20^{\circ} \mathrm{C}$ and $30 \%$ relative humidity $(S L 2)$. $(N=36)$. Standard error.

Regarding to the delta b results (Figure 9), no clear patterns between the treatments can be concluded. It seems that the cultivar effect was much stronger than any effect of coating or shelf life conditions. The cultivars A-Late and $\mathrm{C}$ were getting slightly more yellow (Delta b positive) during the storage period. This may be resulting of variation in the ripening stage/speed of the used apple batches.

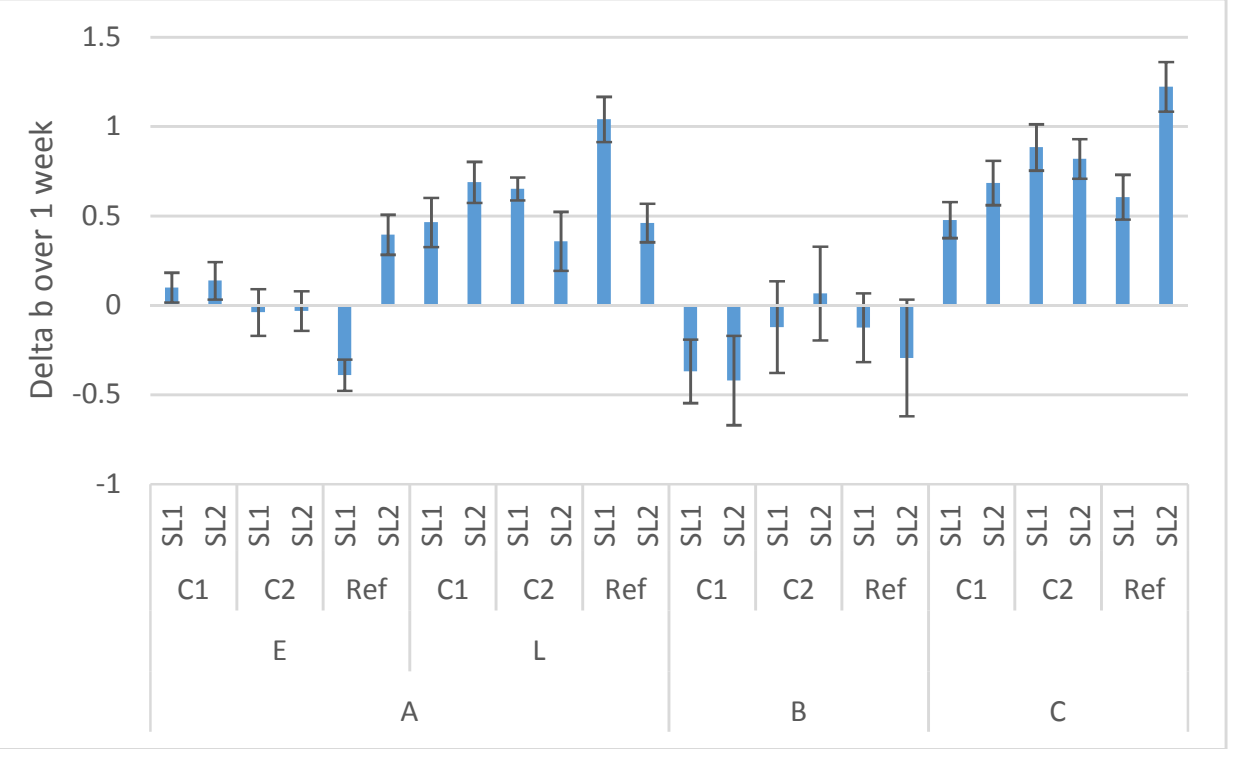


Figure 10: Delta b values of the yellow part of apples. Apples were untreated (ref), treated with coating 1 or 2 prior storage and stored at $20^{\circ} \mathrm{C}$ and highr relative humidyt (SL1) or 20 $\mathrm{C}$ and lower relative humidity (SL2). $(N=36)$ Standard error.

\section{$3.5 \quad$ Firmness}

The two shelf life conditions do not affect the average firmness after 8 days of storage. However there is a statistical difference in the average firmness for the coated and not coated (reference): the apples with coating 1 showed a significant higher firmness than the uncoated apples Figure 10). This difference is however very limited $(<0.2 \mathrm{~kg}$ ). There is no difference in firmness between the 2 coatings: coating 2 does not lead to firmer apples than uncoated apples.

As it could be expected the firmness is significant different for the 4 batches; batches A_E and A_L were evenly firm and more firm than $B$ and $C$ ( $B$ and $C$ are also equally firm) (data not shown). There no statistical interactions between the 3 parameters cultivar-origin; treatment and shelf life.

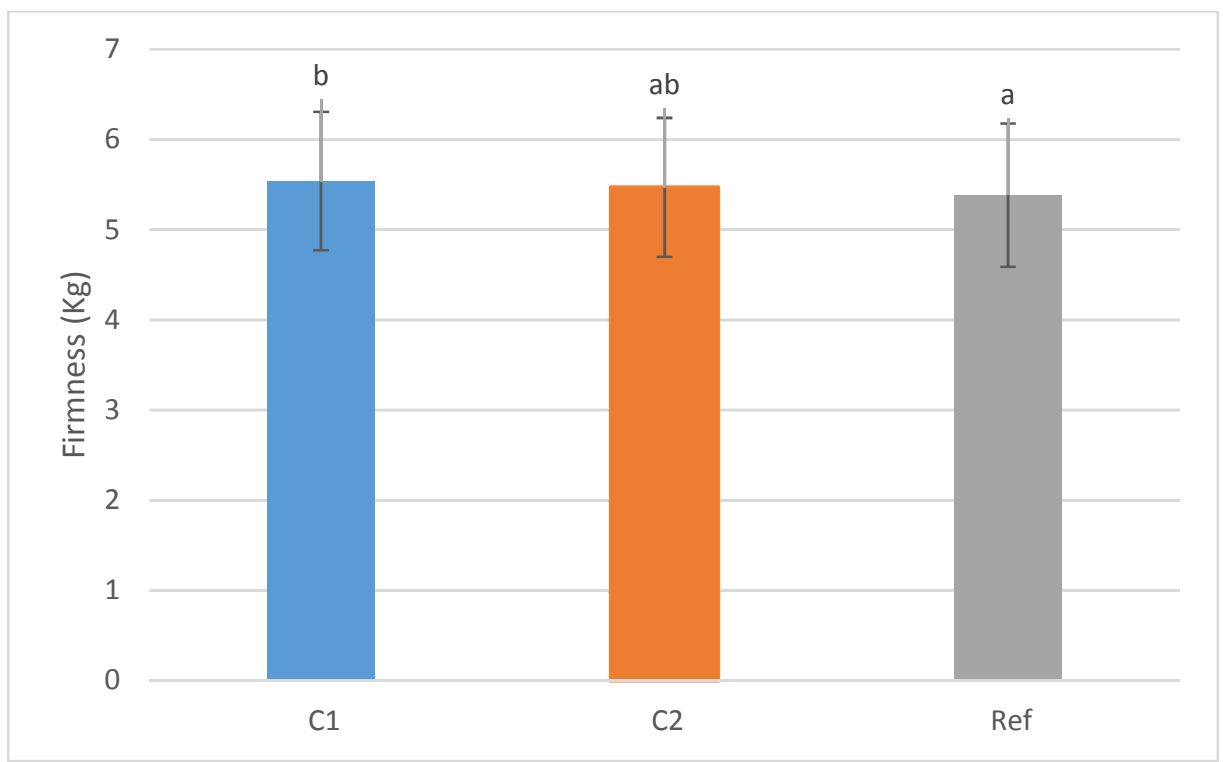

Figure 11: Average firmness of the three treatments $(N=16)$; Significant difference per batch are indicated by the letters (Turkey test, $P<0.05$ ).

\subsection{Quality defects}

Skin spots

The amount of skin spots was scored visually using a class scale. Since the class scale is not continuous, the variable is not normally distributed. For this reason, it is not possible to carry out an analysis of variance on the results. The plot in Figure 11 shows the results. The standard deviation is large ranging from 0 to $26 \%$ (data not shown). The graph does not show clear trends either, therefore it seems that there is no effect of the coating or shelf life on the amount of the skin spots. 


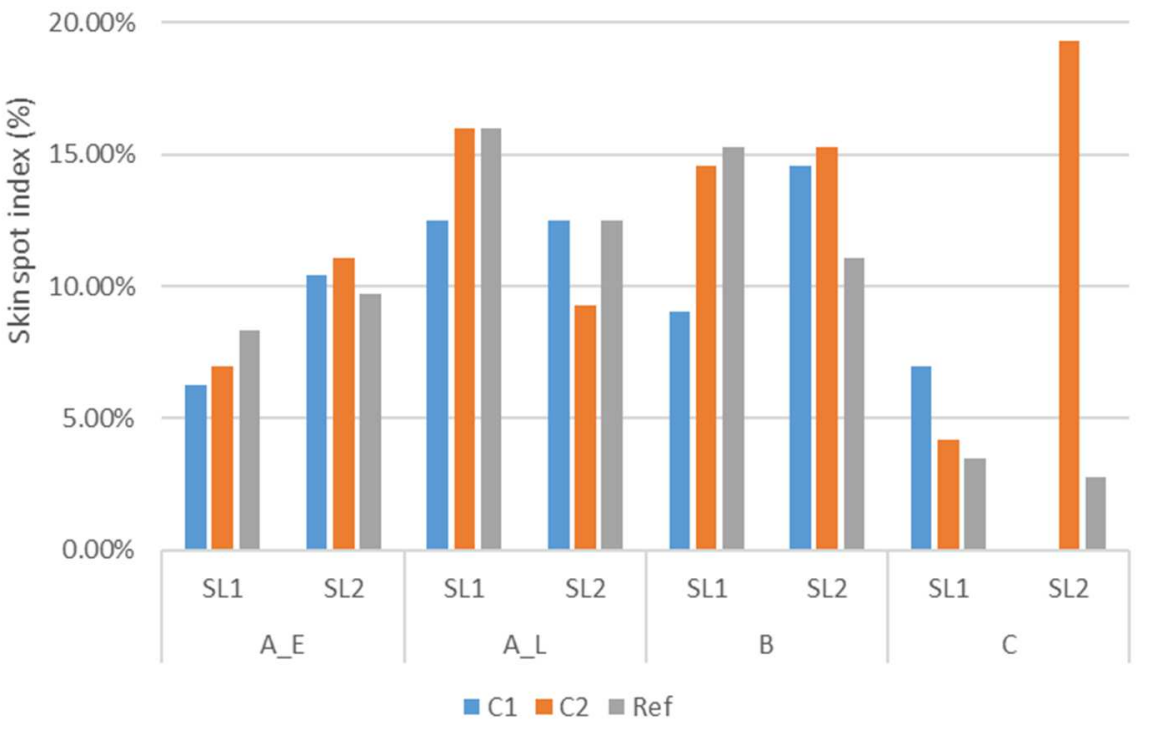

Figure 12: Skin spot index observed after one week shelf life period (SL1, SL2) on apples cultivars $A \_E, A \_L, B$ and $C$ treated with coating $1(C 1$,$) coating 2$ (C2) or without coating (Ref). $(N=36)$. Batch $A \_E, A \_L$ and $B$ are the same mutant (Excellent) with respectively early, late and late harvest; batch $C$ is the mutant Elrosa from early harvest.

\section{Senescence Breakdown}

The variable senescence breakdown is scored as present $(=1)$ and not present $(=0)$ for each apple. The percentage of senescence breakdown is calculated by dividing the number of apples showing senescence breakdown by the total number of apples. The results are presented in Figure 12. The statistical analysis showed that there are not significant differences between the treatments (with or without coating) neither between the two shelf life conditions. Only between the batches is the amount of senescence breakdown significantly different: batch B has the most senescence breakdown compared to the other batches; the other batches do not differ from each other though.

The level of glossiness after storage was not measured or noted as observation. 


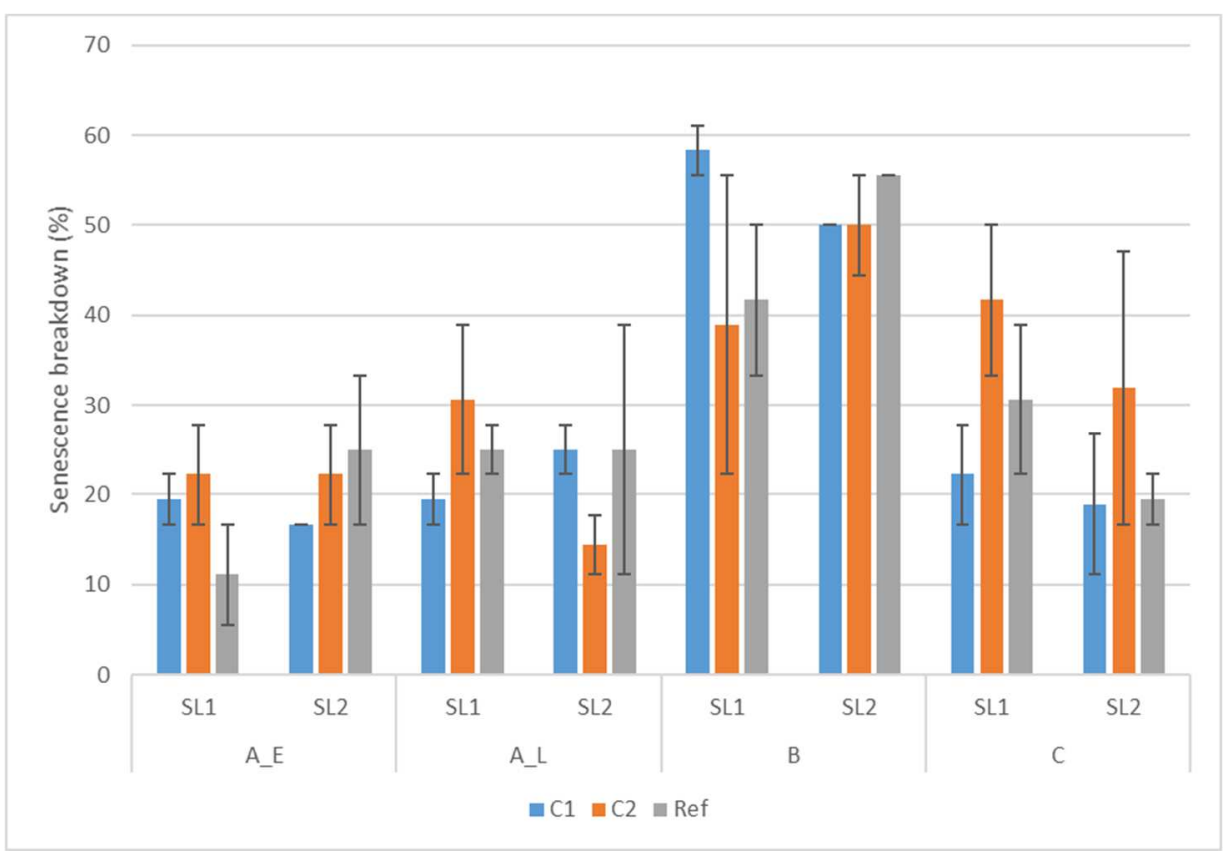

Figure 13: Percentage of senescence breakdown observed after one week shelf life period (SL1, SL2) on apples cultivars $A \_E, A \_L, B$ and $C$ treated with coating 1 (C1,) coating 2 (C2) or without coating (Ref). ( $N=36)$. Standard deviation. Batch A_E, A_L and B are the same mutant (Excellent) with respectively early, late and late harvest; batch $C$ is the mutant Elrosa from early harvest.

\section{Lenticel rot}

This quality defect was also scored as present $(=1)$ and not present $(=0)$ for each apple and the data analysis was carried out exactly the same way as the senescence breakdown. The results are presented in Figure 13. The statistical analysis showed that there are not significant differences between the treatments (with or without coating) neither between the two shelf life conditions. Rot development is mostly enhanced at high humidity. Since the RH of both shelf life conditions was relatively low, no differences between the shelf life conditions may be expected. Only between the batches is the amount of senescence breakdown significantly different: batch B has the most senescence breakdown compared to the other batches; the other batches do not differ from each other though.

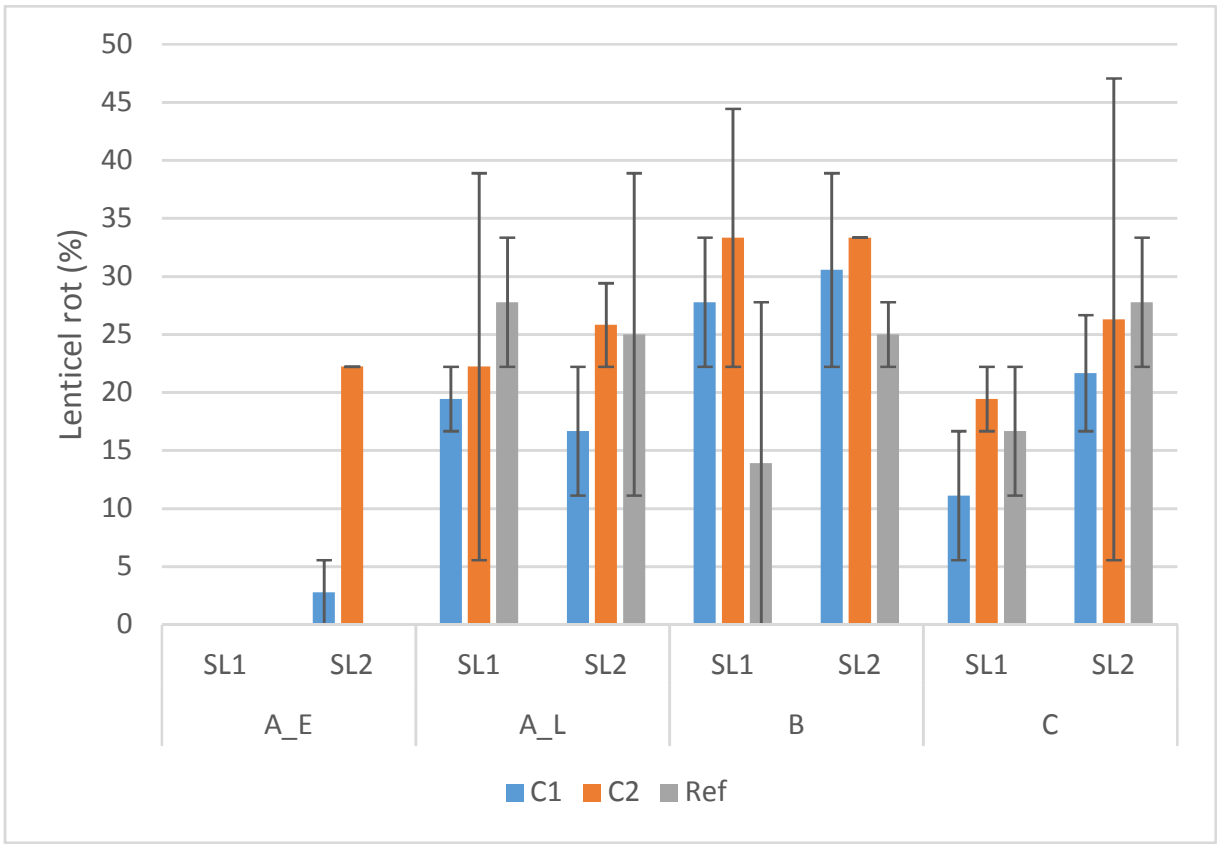


Figure 14: Percentage of lenticel rot breakdown observed after one week shelf life period (SL1, SL2) on apples cultivars A_E, A_L, B and C treated with coating 1 (C1,) coating 2 (C2) or without coating (Ref). $(\mathrm{N}=36)$. Standard deviation.

Other defects

The apples were inspected one by one and other internal defects as flesh rot, core infection, ULO (Ultra High Oxygen) damage and eventual other observations were noted. There were a few ULO damage apples observed by the A_E batch: in total 7 apples out of 216 . This low incidence combined with large biological variation makes it not relevant and not suited for proper statistical evaluation. For the other batches no ULO damage was observed. Apples with core infection were even less: 3 in total for all batches (for all batches together 859 apples were measured in total). Finally, there was significant rot: in total $5 \%-7 \%$ of the fruits after shelf life. The apples with rot were found both in the coated and uncoated apples, indicating that the coating does not affect the development of rot during shelf life.

In some cases the coated apples were sticky, giving an unpleasant and unnatural feel to the fruits ( both with the $\mathrm{C} 1$ as well as with the $\mathrm{C} 2$ concentration). This is an important observation, the coating formulation and application should be adapted to prevent this, because it can have serious negative commercial implications. However far most apples were not sticky enough to be noted as such.

\subsection{Sensorial analysis}

The results are presented in the Figure 14. In average all samples were judged acceptable (the acceptance limit was set at score 5). The results do not show a clear trend and the differences are not significant. It does not possible to conclude about any positive or negative effects on the odour or taste of the apples.

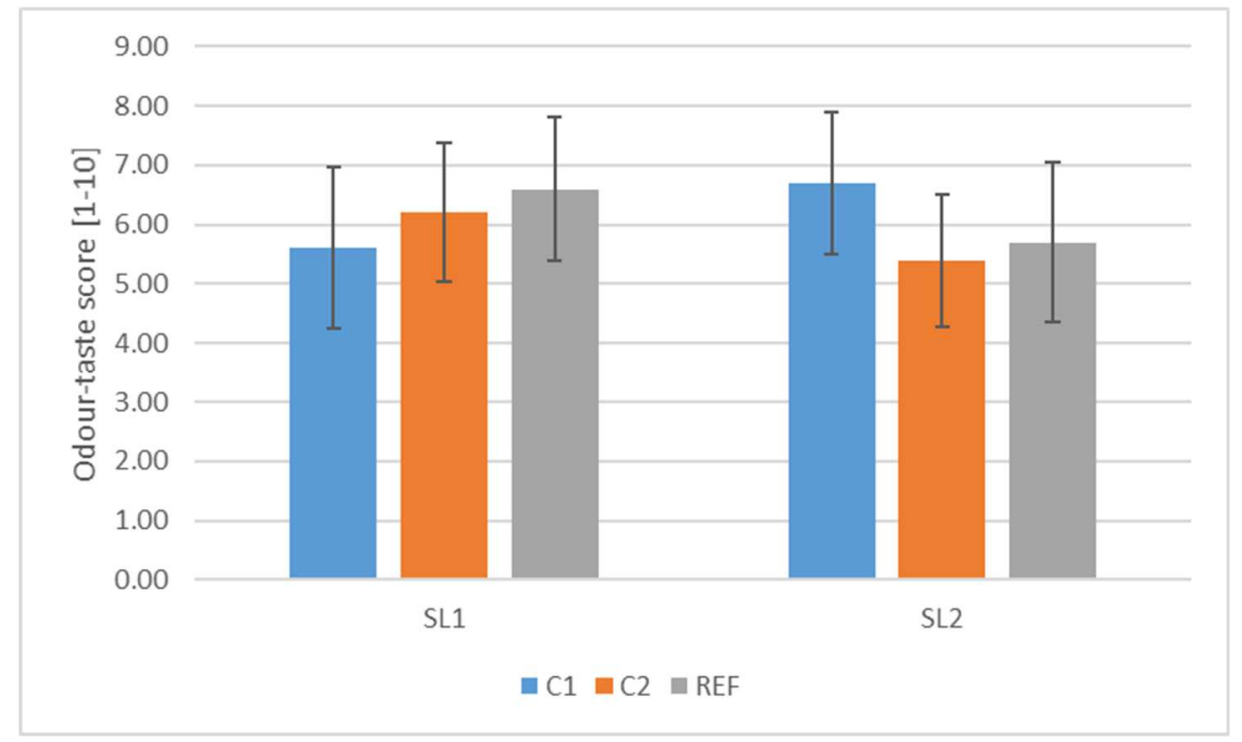

Figure 15: Odour-taste score of A_E apples treated with coating 1 and 2 or non-coated (Ref) and stored for 1 week in shelf life 1or 2. Average given by a panel of 5 people $(N=10)$. Standard deviation.

Next to the score, the panellists were asked to note eventual remarks. Some remarks were made regarding the texture and the taste both for the coated and not coated samples. Therefore also in the qualitative sensorial assessment there are no differences between the coating and the reference. 


\section{Conclusions}

The main goal of this research was to evaluate the effect of applying a starch based coating on the quality and shelf life of apples. For a storage period of 8 days at $20^{\circ} \mathrm{C}$ and around $65 \%$ or $42 \%$ relative humidity and for the tested apple batches, the coating has a marginal effect on shelf life:

\section{Firmness}

The firmness of the $\mathrm{C} 1$ coated apples is statistically higher than the uncoated and the C2 coated apples. The difference found is however very limited $(<0.2 \mathrm{Kg})$ and eventually not commercially relevant.

\section{Colour}

No significant effect of the coating on the yellowing of the apples was found (yellowing is a relevant quality indicator; the more yellow the riper the apple). A significant effect of the coating on the other colour parameters was observed during the shelf life period: coated apples were slightly darker and more red after one week of storage compared to the uncoated apple. These colour parameters are however not directly linked to the physiological shelf life of apples.

Internal and external disorders

For all other quality parameters assessed there is no difference between the coated and uncoated apples. This includes rot, core flush, senescent breakdown, skin spots and other external/internal disorders

\section{Weight loss}

The weight loss results may be biased (if the coating was not fully dried yet, the moisture loss measured may be also from the coating). Therefore no conclusions should be drawn regarding the weight loss.

\section{Sensorial assessment}

The sensorial evaluation of the coated fruit is very relevant as the application of a coating may not lead to undesirable off-odours or off-taste. The application of this starch coating did not have a negative neither positive effect on the sensorial perception (odour and taste) of the A_E batch apples. All samples were scored above the acceptance limit regardless of the presence of a coating and the thickness of the coating.

The research was carried out with apple batches of two different Elstar mutant (Excellent and Elrosa) and in different physiological development stages. The batch B showed more senescence breakdown, more lenticel rot and was less firm. The effect of the coating does not seem to depend on the development stage of the apples. Moreover the differences between the apple batches were larger than between coated and uncoated apples.

Based on the results it can be concluded that the thickness of the coating is relevant. The significant difference in firmness was only found for the thicker coating (firmer than the uncoated apples), indicating that the current formulation could be improved by applying a thicker or more concentrated coating layer. There is no difference in firmness and other quality attributes between the thinner coating and the uncoated apples.

On the day after the coating application, the coated apples seemed to have higher gloss than uncoated apples (This is a general observation; the level of glossiness was not scored).

These conclusions apply for the scope of this test (cultivar, maturity level, storage conditions, etc). Other cultivars or longer storage periods may lead to different conclusions. However no extrapolations for other situations can be done based on the current research. 


\section{Recommendation}

Under the tested conditions there was only a marginal difference found in the firmness and all other quality parameters were not affected by the coating. The shelf life period was 8 days. When keeping the apples for a longer storage period the effect of the coating could be more pronounced. Therefore it could be relevant to test the coating for other (longer) shelf life periods.

The tests were carried out with apples which were stored already for 8-9 months. Based on these results it cannot be fully extrapolated what the effect of the coating would be on apples just after harvesting. The effect of the coating might be larger under these conditions when the apples are firmer and physiological more active.

The significant difference in firmness was only found for the thicker coating hence the current formulation could be improved by applying a thicker or more concentrated coating layer. At the same time the stickiness observed in some of the coated fruits should be tackled in future formulations.

A simulation of the industrial coating application has been used in this research. Under optimised industrial conditions (for instance other drying process) the performance of the coating might be different. Additional research on the effect of the process on the coating performance is therefore recommended. 


\section{Annex 1: Questionnaire sensorial evaluation}

Sensorial evaluation of 12 apple samples

1) Smell and taste at least 2 pieces of apple per sample. 2) Give a score* to the taste and odour of the sample. 3) Please add your remarks/opinion over the taste, odour and/or visual appearance of the samples.

* Score 1 - 10: $\quad 1$ = Very bad

$5=$ Still acceptable

$10=$ Excellent

1.Sample number:

Remarks:

2. Sample number:

Score:

Remarks:

Score:

3. Sample number

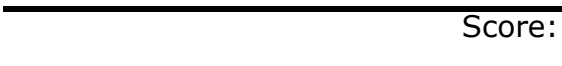

Remarks:

4. Sample number:

Score:

Remarks:

5. Sample number:

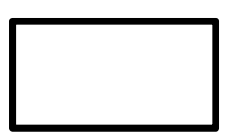

Remarks:

6. Sample number:

Score:

Remarks:

Score:

7. Sample number:

(n)

Remarks:

8. Sample number:

Score:

Remarks:

Score:

9. Sample number:

Score:

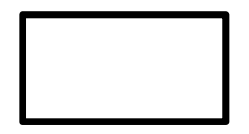




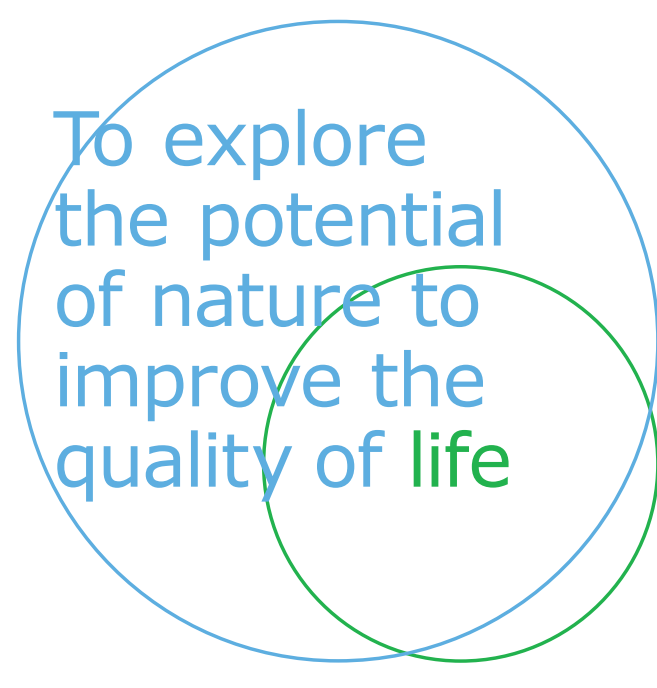

Wageningen Food \& Biobased Research Bornse Weilanden 9

6708 WG Wageningen

The Netherlands

www.wur.eu/wfbr

E info.wfbr@wur.nl

Report 1840

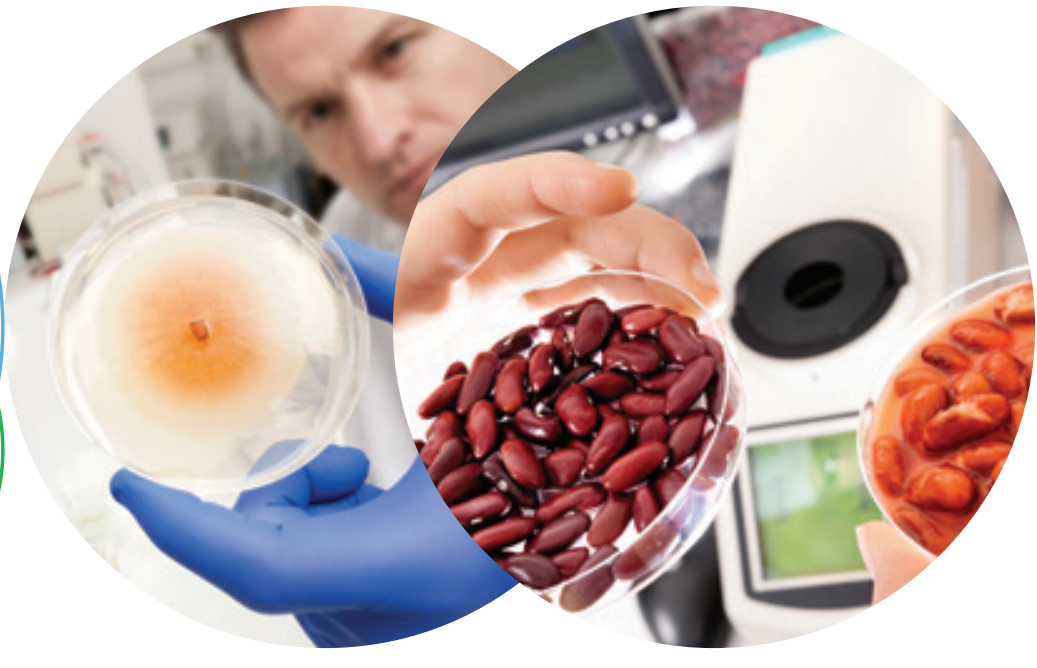

The mission of Wageningen University and Research is "To explore the potential of nature to improve the quality of life". Under the banner Wageningen University \& Research, Wageningen University and the specialised research institutes of the Wageningen Research Foundation have joined forces in contributing to finding solutions to important questions in the domain of healthy food and living environment. With its roughly 30 branches, 5,000 employees and 10,000 students, Wageningen University \& Research is one of the leading organisations in its domain. The unique Wageningen approach lies in its integrated approach to issues and the collaboration between different disciplines. 